\title{
Horst Hilger:
}

\section{Zentralkatalog Baden-Württemberg legt Schwerpunkt auf den Nachweis der Altbestände}

Die in der Südwest-Region vorhandenen Titel seit circa 1958 sind nahezu vollständig von den Bibliotheken in den regionalen Verbundkatalog, den SWB, eingebracht worden. Deshalb hat das Bibliotheksservice-Zentrum BadenWürttemberg (BSZ) im Januar 2006 eine Stuttgarter Firma damit beauftragt, etwa ein Drittel der konventionellen Bestandsnachweise (Katalogzettel) des Zentralkatalogs in Stuttgart zu entsorgen. Es handelt sich dabei um den Neuen Verfasserkatalog mit dem Berichtszeitraum 1958 - 1991 und das Nachmeldealphabet zum Sachtitelkatalog mit dem Berichtszeitraum 1984 - 1991 mit insgesamt 3,5 Mio. Katalogzetteln, die fast ohne Informationsverlust makuliert werden konnten. Zudem existiert mit dem Mikrofiche-Verfasserkatalog 1958 - 1983, der 1986/87 von zahlreichen Bibliotheken erworden wurde und der im Stuttgarter Zentralkatalog ebenfalls zur Verfügung steht, ein Ersatzmedium für den größten Teil der makulierten Bestandsnachweise. Erhalten bleiben weiterhin der Alte Verfasserkatalog (Berichtszeitraum 1500 - 1957) und der Sachtitelkatalog (Berichtszeitraum 1500 - 1983) mit insgesamt 8,5 Mio. Katalogzetteln, in denen die kompletten Altbestandsnachweise der Südwest-Region bis zum Erscheinungsjahr 1900 enthalten sind. Nicht nur die Nachweise der großen "alten" Universitäts- und Landesbibliotheken, die zum erheblichen Teil durch die DFG-geförderten Konversionsprojekte in den SWB eingebracht worden sind, sondern auch die der zahlreichen theologischen Spezial-, Adels- und Stadtbibliotheken mit wissenschaftlichem Altbestand sind für die Bibliothekslandschaft Südwestdeutschlands prägend. Vor allem diese Nachweise sind noch nicht im SWB enthalten. Ein ausführliches Gutachten des Freiburger Wissenschaftlers Prof. Dr. Reinhart Siegert hat noch einmal eindrucksvoll die Bedeutung des Zentralkatalogs Baden-Württemberg für den Nachweis der Altbestände in seiner Region bestätigt: er ist eine Art Schlüssel zu den im "Handbuch der Historischen Bibliotheksbestände" summarisch aufgeführten Beständen der kleineren Bibliotheken in Baden-Württemberg für den Zeitraum bis 1900. Zur Teil-Makulierung des ZKBW erschien am 19.01.2006 ein Artikel in den Stuttgarter Nachrichten (s. Pressespiegel in diesem Heft). 